\title{
Öğretmenler İçin Yenilikçi Pedagoji Uygulamaları Ölçeği: Geçerlik ve Güvenirlik Çalışması*
}

\section{Innovative Pedagogical Practices Scale for Teachers: A Study of Validity and Reliability}

\author{
Sedef SÜER**, Behçet ORAL***
}

Öz: Bu çalışmada öğretmenlerin yenilikçi pedagoji uygulamalarını belirlemeye yönelik bir ölçme aracının geliştirilmesi amaçlanmaktadır. Bu amaç doğrultusunda hazırlanan taslak ölçek Diyarbakır ili merkez ilçelerine bağlı ilkokullarda görev yapan toplam 463 sınıf öğretmenine uygulanmış ve toplanan veriler üzerinde geçerlik ve güvenirlik analizleri gerçekleştirilmiş̧ir. Açımlayıcı faktör analizi sonucunda toplam varyansın \%36'sını açıkladığı ve 46 maddelik tek boyuttan oluştuğu belirlenen “Öğretmenler İçin Yenilikçi Pedagoji Uygulamaları Ölçeği” doğrulayıcı faktör analizi ile sınanmıştır. Ölçeğin Cronbach alfa iç tutarlık katsayısı ise 0,95 olarak belirlenmiştir. Yapılan analizler neticesinde öğretmenlerin yenilikçi pedagoji uygulama düzeylerini tespit etmek amacıyla kullanılabilecek güvenilir ve geçerli bir ölçme aracı elde edilmiştir.

Anahtar Kelimeler: Yenilikçi pedagoji, öğretmen, ölçek geliştirme.

Abstract: The aim of this study is to develop a scale to determine teachers' innovative pedagogical practices. For this purpose, a draft scale was designed and applied to 463 primary school teachers working in primary schools in Diyarbakir. Then, the validity and reliability analyses were performed on the data obtained. As a result of the analyses, the "Innovative Pedagogical Practices Scale for Teachers" consisting of 46 items with a single dimension and explaining $36 \%$ of the total variance was confirmed with CFA. The Cronbach alpha internal consistency coefficient of the scale was found to be .95 . As a result, a reliable and valid Innovative Pedagogical Practices Scale for Teachers was developed to determine teachers' innovative pedagogical practices.

Keywords: Innovative pedagogy, teacher, scale development.

\section{Giriş}

Küreselleşme, çağımız ülkeleri arasında bir yandan rekabete yol açarken, bir yandan da bu ülkelerin işbirliği içinde çalışmalarını gerekli kılmıştır. Bugün az gelişmiş ve gelişmekte olan ülkeler, gelişmiş ülkelere yetişme amacı güderken, gelişmiş ülkeler ise belirli teknolojilere yön vererek ileri bir teknolojiyi ve güçlü bir ekonomiye sahip olmak için çaba sarf etmektedir. Sürdürülebilir ve gelişmiş bir ekonomi de yenilikçi bir anlayışı gerekli kılmaktadır (Vikas, 2012). Çünkü artan ve hızla ilerleyen bir sistemde becerikli ve donanımlı bir işgücüne ihtiyaç duyulmaktadır. $\mathrm{Bu}$ işgücünün sağlanabilmesi de ancak çağa ayak uydurabilen bir eğitim anlayışıyla mümkün olabilmektedir (Dawe, 2004).

Küresel ekonomide eğitimle işbirliği içinde olan bir yenilik süreci bugünün dünyasının olmazsa olmazları olarak kabul edildiğinden eğitimde yenileşme kuramı bilimsel pedagojinin yeni bir çalışma alanı olarak ortaya çıkmıştır (Stukalenko, Zhakhina, Kukubaeva, Smagulova ve Kazhibaeva, 2016). Eğitimde yenilik, standart uygulamalardan kaçınıp eşit veya daha az zaman ve kaynak kullanımıyla öğlencilerde daha büyük öğrenme ürünleri oluşturmayı hedefleyen bir anlayıştır (Redding, Twyman ve Murphy, 2013). Yenilik kuramı, eğitim sistemindeki yenilikçi süreçlerle ilgilenmektedir. Yenilikçi süreçler ise yenilikçi öğrenme etkinlikleri, yenilikler ve yenilikçi öğrenme ortamları aracılığıyla ortaya çıkmaktadır (Stukalenko vd., 2016).

\footnotetext{
*Bu çalışma, Dicle Üniversitesi'nde Haziran 2019 tarihinde tamamlanan ve birinci yazarın, ikinci yazar danışmanlığında gerçekleştirdiği doktora tezinden üretilmiştir.

**Dr. Dicle Üniversitesi, Ziya Gökalp Eğitim Fakültesi, Diyarbakır-Türkiye, ORCID: 0000-0002-1833-9286, e-posta: sedefsuer@gmail.com

***Prof. Dr., Dicle Üniversitesi, Ziya Gökalp Eğitim Fakültesi, Diyarbakır-Türkiye, ORCID: 0000-0002-6885-1683, e-posta: oralbehcet@gmail.com
} 
Eğitim ortamında iki tür yenilik olgusundan söz edilmektedir. Bunlar Yeniliğin Öğrenilmesi (Innovation Learning) ve Pedagojik Yenilik Kuramı (Pedagogical Innovation Theory) olarak ifade edilmektedir. Yeniliğin öğrenimi, eğitsel süreçlerdeki bilinçli, hedef odaklı ve bilimsel bulgulara dayanan etkinlikler sonucunda oluşturulan özel bir bilgi yapılandırma yöntemi olarak ifade edilirken, Pedagojik yenilik kuramı, eğitim sisteminin veya sistemin karakteristik özellikleri, yasaları, yönetmelikleri, öğrenme paradigma ve modelleri gibi belirli kısımlarının yeniden yapılandırılması, düzenlenmesi, geliştirilmesi veya değiştirilmesini kapsamaktadır (Stukalenko vd., 2016).

Pedagojik yenilik kuramı ve yeniliğin öğrenilmesi kavramlarının yanı sıra çok sık rastlanılan diğer bir kavram ise yenilikçi pedagoji kavramıdır. Bu kavrama ilişkin mutlak bir tanım vermek kolay olmasa da yenilikçi pedagoji sınıf içinde mümkün olan tüm teknolojinin öğrenme ve öğretme süreci ve yaklaşımları içerisinde farklı şekillerde kullanılmasını vurgular (Salmon, 2005). Böylelikle öğrenme öğretme ortamında alternatif uygulamaların geliştirilmesine olanak sağlayarak (Edwards ve Bone, 2012) öğrenci merkezli eğitim anlayışının uygulanmasına yardımcı olur. Yenilikçi pedagojide teknoloji kullanımı önemli bir unsur olmasına rağmen eğitimdeki yenilik teknolojik cihazların kullanımında ibaret değildir (Redding, Twyman ve Murphy, 2013). Eğitimde yenilik, mevcut eğitsel amaçlara ulaşmak veya eğitsel problemleri çözmek için keşfedilen veya icat edilen bir yeniliğin eğitsel ortamda bir fikir, yöntem veya materyal olarak kullanılmasıdır (Rusdiana, 2014). Bununla birlikte günümüz okullarındaki öğrenciler, teknolojiyi ileri düzeyde kullanma becerisine sahip iken, yaratıcı ve ikna edici iletişim kurma ve analiz etme, sentez ve değerlendirme yapma becerilerini kullanarak teknolojiyi kullanma konularında yeterli donanıma sahip değildir (Williamson, 2011). Bu açıdan bakıldığında, yenilikçi pedagojinin sınıf içindeki öğrencilere mevcut teknolojiler aracılığıyla söz konusu becerileri kazandırmayı hedeflediği, bu yönüyle de geleneksel teknoloji destekli öğretimden farklılık gösterdiği anlaşılmaktadır.

Eğitim sistemine dahil olan öğrenci özellikleri incelendiğinde eğitimciler ve eğitim yorumcuları bir önceki nesilden farklı yeni bir neslin eğitim sistemine girdiğini ifade etmektedir. Dijital yerliler veya internet nesli olarak adlandırılan bu kuşağın tüm yaşamları boyunca teknolojiyle iç içe oldukları için (McCrindle ve Wolfinger, 2009) geleneksel eğitimin hazırlıksız olduğu karmaşık teknik beceriler ve öğrenme tercihlerine sahip oldukları belirtilmektedir. Bu yüzden geleneksel eğitimin bu kuşağın ihtiyaçlarına cevap vermede yetersiz kaldığg iddia edilmektedir (Karadoğan, 2019; Kavalcı ve Ünal, 2016).

Öğrenci profilinin değişmesi, yeni teknolojilerin etkisi ve iş dünyasının değişen talepleri, okullarda verilen eğitim ve öğretimi de etkilemektedir (Katitia, 2015; Bennett, Maton ve Kervin, 2008). Benimsenen eğitim anlayışına paralel olarak okullarda verilen eğitimin gerçek yaşam koşullarını desteklemesi ve yenilikçi becerileri geliştirmesi gerekmektedir (Jirasatjanukul ve Jeerungsuwan, 2018). Bu durum öğretmenlere sınıf ortamında yenilikçi pedagojiye yönelik uygulamalar yaparak öğrencilerde yenilikçi beceriler geliştirme sorumlululuğu yüklemektedir. Çünkü öğretmenler toplumun ihtiyaç duyduğu bilgi, beceri ve niteliklere sahip bireyler yetiştirmede kilit rol oynamaktadır (Prachagool, Nuangchalerm, Subramaniam ve Dostál, 2016; Karataş, 2020). Öğretmenlerin yenilikçi uygulamalarını konu alan çalışmalar incelendiğinde, ilgili alanyazında öğretmenlerin yenilikçilik düzeylerinin Hurth, Joseph ve Cook (1977) tarafından geliştirilmiş, bireyleri bir yeniliğe tepki verme veya benimseme durumuna göre sınıflayan "Bireysel Yenilikçilik Ölçeği"nin kullanıldığı görülmektedir. Bu ölçek, bireysel yenilikçiliği ölçmeyi amaçlasa da öğretmenlerin eğitim ortamındaki yenilikçi uygulamaları konusunda bir veri sağlayamamaktadır. Ayrıca yurt içi alanyazında Kocasaraç ve Karataş (2018) tarafından geliştirilmiş 53 madde ve 4 faktörden oluşan "Yenilikçi Öğretmen Özellikleri Ölçeği" ile Altıntaş-Yüksel ve Gelişli (2018) tarafından geliştirilen 52 madde ve 3 faktörden oluşan "Sınıf Öğretmenlerinin Mesleki Yenilikçilik Ölçeği” bulunmaktadır. Yenilikçi pedagoji kapsamında değerlendirildiğinde yenilikçi öğretmen, yenilikçi pedagojinin bir kolunu oluştururken sınıf içindeki yenilikçi öğrenme ve öğretim uygulamaları ise diğer kolunu oluşturmaktadır (What is 
Innovative Pedagogy, 2011). Bu bağlamda düşünüldüğünde öğretmenlerin sınıf içindeki yenilikçi öğretim uygulamalarını konu alan bir ölçeğe rastlanılmadığından bu araştırmada öğretmenlerin yenilikçi pedagoji uygulamalarını konu alan ve bu uygulamaları ne sıklıkta kullandıklarını belirleyebilecek bir ölçme aracı geliştirmek amaçlanmıştır.

\section{Yöntem}

Çalışmanın bu bölümünde araştırmanın çalışma grubu, ölçme aracının geliştirilmesi ve verilerin analizinde kullanılan tekniklere ilişkin açıklamalara yer verilmiştir.

\section{Araştırma modeli}

Öğretmenlerin yenilikçi pedagoji uygulamalarına ilişkin görüşlerini ortaya çıkarmak amacıyla kullanılabilecek bir ölçme aracının geliştirilmesini amaçlayan bu çalışmada genel tarama modeli kullanılmıştır. Genel tarama modeli, belirli bir sayıda bir değişkenin sıklığını dağılımını veya ilişkisini kendi doğal ortamında ölçmek için kullanılan bilimsel bir araştırma modelidir (Wiersma, 1995).

\section{Çalışma grubu}

Araştırmanın çalışma grubunu, 2017-2018 eğitim-öğretim yılı Diyarbakır ili merkez ilçelerine bağlı ilkokullarda görev yapan toplam 463 sınıf öğretmeni oluşturmaktadır. Çalışma grubunun seçiminde, pedagoji kavramı çocukları eğitme sanatı veya bilimi anlamında kullanıldı̆̆ından (Knowles, 1970; Akyüz, 1991; Beetham ve Sharpe, 2013), küçük yaştaki çocuklarla öğretim ortamında daha fazla zaman geçiren sınıf öğretmenleri tercih edilmiştir. Ayrıca veri toplamak için sınırlı zamanın olması, ekonomiklik yönünden avantaj sağlaması, kolay ulaşılabilirlik ve geri dönüş oranı fazla olacağı düşüncesiyle çalışma grubu olarak Diyarbakır ilinin dört merkez ilçesinde görev yapan sınıf öğretmenleri belirlenmiştir. Tablo 1'de çalışmaya katılan sınıf öğretmenlerinin betimsel özelliklerine ilişkin dağılımı verilmiştir.

Tablo 1

Çalışmaya Katılan Sını Ö̆ğretmenlerinin Betimsel Özelliklerine Göre Dă̆glımı

\begin{tabular}{|c|c|c|c|c|c|c|}
\hline $\begin{array}{c}\text { Cinsiyet } \\
N \\
\% \\
\end{array}$ & $\begin{array}{c}\text { Kadın } \\
210 \\
45,4 \\
\end{array}$ & $\begin{array}{c}\text { Erkek } \\
253 \\
54,6 \\
\end{array}$ & $\begin{array}{c}\text { Toplam } \\
463 \\
100 \\
\end{array}$ & & & \\
\hline $\begin{array}{c}\text { Eğitim Düzeyi } \\
N \\
\%\end{array}$ & $\begin{array}{c}\text { Önlisans } \\
24 \\
5,2 \\
\end{array}$ & $\begin{array}{c}\text { Lisans } \\
402 \\
86,8\end{array}$ & $\begin{array}{c}\text { Lisansüstü } \\
37 \\
8 \\
\end{array}$ & $\begin{array}{c}\text { Toplam } \\
463 \\
100 \\
\end{array}$ & & \\
\hline $\begin{array}{c}\text { Kidem } \\
N \\
\% \\
\end{array}$ & $\begin{array}{c}1-5 \mathrm{y} 1 \mathrm{l} \\
85 \\
18,4\end{array}$ & $\begin{array}{c}6-10 \mathrm{y} 1 \mathrm{l} \\
85 \\
18,4\end{array}$ & $\begin{array}{c}11-15 \text { y1l } \\
89 \\
19,2 \\
\end{array}$ & $\begin{array}{c}16-20 \text { y1l } \\
99 \\
21,4 \\
\end{array}$ & $\begin{array}{c}21 \text { yıl ve üzeri } \\
105 \\
22,7\end{array}$ & $\begin{array}{c}\text { Toplam } \\
463 \\
100\end{array}$ \\
\hline
\end{tabular}

Araştırmanın çalışma grubu incelendiğinde, katılımcı sınıf öğretmenlerinin \% 45' inin $(\mathrm{N}=210)$ kadın, \% 54'ünün $(\mathrm{N}=253)$ erkek olduğu ve yine sınıf öğretmenlerinin yaklaşık \% $87(\mathrm{~N}=402)$ ile büyük çoğunluğunun lisans mezunu oldukları saptanmıştır. Ayrıca çalışmaya katılan sınıf öğretmenlerinin mesleki kıdem dağılımına bakıldığında dengeli bir dağılım gözlenmekle birlikte sınıf öğretmenlerinin yaklaşık \% 23 'ünün $(\mathrm{N}=105) 21$ yıl ve üzeri mesleki kıdeme sahipken \%18'inin ise $(\mathrm{N}=85) 1$ ile 5 yıl arası mesleki tecrübeye sahip olduğu görülmektedir.

\section{Ölçek geliştirme işlemleri}

Çalışmada öğretmenlerin yenilikçi pedagoji uygulamalarını ölçebilecek bir ölçme aracı geliştirebilmek amacıyla öncelikle alan yazın incelemesi yapılmıştır. Yurt içi ve yurt dış1 alanyazında benzer nitelikte bir ölçeğe rastlanılmadığından "bireysel yenilikçilik", "yenilikçi davranışlar" ve "yenilikçi pedagoji" kavramları üzerindeki bilimsel araştırmalar (Hughes, 2005; 
Öğretmenler İçin Yenilikçi Pedagoji Uygulamaları Ölçeği: Geçerlik ve Güvenirlik Çalışması

Kılıçer ve Odabaşı, 2010; Konokman, Yokuş ve Yelken, 2016; Çimen ve Yücel, 2017; Kocasaraç ve Karataş, 2018) incelenmiştir. Alanyazın incelenmesi sonucunda 50 maddeden oluşan bir madde havuzu oluşturulmuştur. Madde havuzunda yer alan yenilikçi pedagoji uygulamalarına ilişkin 50 madde ve 10 sorudan oluşan kişisel bilgi formu, Büyüköztürk, Çakmak, Akgün, Karadeniz ve Demirel (2013) tarafindan oluşturulan uzman değerlendirme formuna aktarılmış ve farklı üniversitelerde görev yapan iki ölçme ve değerlendirme, üç eğitim yönetimi, iki dil eğitimi ve dört eğitim programları ve öğretim alanında çalışan 11 uzmanın incelemesine sunulmuştur. Uzmanlardan gelen dönütler neticesinde her bir maddeye ilişkin uygunluk düzeyi hesaplanmış ve bulgular Tablo 2'de sunulmuştur.

Tablo 2

Veri Toplama Aracında Yer Alan Maddelerin Uygunluk Oranlart

\begin{tabular}{|c|c|c|c|c|c|}
\hline Maddeler & $\begin{array}{c}\text { Uygun } \\
\%\end{array}$ & $\begin{array}{c}\text { Uygun Değil } \\
\%\end{array}$ & Maddeler & $\begin{array}{c}\text { Uygun } \\
\%\end{array}$ & $\begin{array}{c}\text { Uygun Değil } \\
\%\end{array}$ \\
\hline $\mathrm{m} 1$ & 81,8 & 18,2 & $\mathrm{~m} 26$ & 100 & 0 \\
\hline $\mathrm{m} 2$ & 81,8 & 18,2 & $\mathrm{~m} 27$ & 81,8 & 18,2 \\
\hline $\mathrm{m} 3$ & 90,9 & 9,1 & $\mathrm{~m} 28$ & 90,9 & 9,1 \\
\hline $\mathrm{m} 4$ & 72,7 & 27,3 & $\mathrm{~m} 29$ & 81,8 & 18,2 \\
\hline $\mathrm{m} 5$ & 90,9 & 9,1 & $\mathrm{~m} 30$ & 81,8 & 18,2 \\
\hline $\mathrm{m} 6$ & 90,9 & 9,1 & $\mathrm{~m} 31$ & 81,8 & 18,2 \\
\hline $\mathrm{m} 7$ & 100 & 0 & $\mathrm{~m} 32$ & 90,9 & 9,1 \\
\hline $\mathrm{m} 8$ & 81,8 & 18,2 & m33 & 81,8 & 18,2 \\
\hline m9 & 90,9 & 9,1 & m34 & 100 & 0 \\
\hline $\mathrm{m} 10$ & 100 & 0 & $\mathrm{~m} 35$ & 90,9 & 9,1 \\
\hline $\mathrm{m} 11$ & 81,8 & 18,2 & $\mathrm{~m} 36$ & 81,8 & 18,2 \\
\hline $\mathrm{m} 12$ & 90,9 & 9,1 & m37 & 100 & 0 \\
\hline $\mathrm{m} 13$ & 100 & 0 & $\mathrm{~m} 38$ & 100 & 0 \\
\hline $\mathrm{m} 14$ & 100 & 0 & m39 & 100 & 0 \\
\hline $\mathrm{m} 15$ & 72,7 & 27,3 & $\mathrm{~m} 40$ & 81,8 & 18,2 \\
\hline $\mathrm{m} 16$ & 63,6 & 36,4 & $\mathrm{~m} 41$ & 90,9 & 9,1 \\
\hline $\mathrm{m} 17$ & 90,9 & 9,1 & $\mathrm{~m} 42$ & 90,9 & 9,1 \\
\hline $\mathrm{m} 18$ & 90,9 & 9,1 & $\mathrm{~m} 43$ & 90,9 & 9,1 \\
\hline $\mathrm{m} 19$ & 90,9 & 9,1 & $\mathrm{~m} 44$ & 90,9 & 9,1 \\
\hline $\mathrm{m} 20$ & 90,9 & 9,1 & $\mathrm{~m} 45$ & 100 & 0 \\
\hline $\mathrm{m} 21$ & 81,8 & 18,2 & $\mathrm{~m} 46$ & 81,8 & 18,2 \\
\hline $\mathrm{m} 22$ & 81,8 & 18,2 & $\mathrm{~m} 47$ & 100 & 0 \\
\hline $\mathrm{m} 23$ & 90,9 & 9,1 & $\mathrm{~m} 48$ & 90,9 & 9,1 \\
\hline $\mathrm{m} 24$ & 100 & 0 & $\mathrm{~m} 49$ & 100 & 0 \\
\hline $\mathrm{m} 25$ & 63,6 & 36,4 & $\mathrm{~m} 50$ & 90,9 & 9,1 \\
\hline
\end{tabular}

Büyüköztürk ve diğerleri (2013), uzmanlardan gelen dönütler neticesinde her bir madde için uyuşma düzeyinin ayrı ayrı hesaplanması ve ölçeğe alınacak maddelerin \%90-100 arasında uyuşma düzeyine sahip olması gerektiğini belirtirken, \%70-80 uyuşma düzeyi gösteren maddeler içinse gelen eleştiriler doğrultusunda düzeltmeler yapılarak ölçekte tutulması gerektiğini vurgulamaktadırlar. Gelen dönütler neticesinde ölçekten iki madde çıkarılıp (m16 ve m25) yeni bir madde yazılmıştır. Ölçekte yer alan sekiz madde ifade açısından uzmanların verdiği öneriler 1şı̆̆ında yeniden yazılmış ve 18 maddede ise sözcük bazında düzeltmelere gidilmiştir. Uzman görüşleri neticesinde 49 maddeden oluşan ölçek beşli Likert şeklinde "her zaman", "sıklıkla", "ara sıra", "nadiren", "asla" şeklinde derecelendirilmiştir.

\section{Verilerin toplanması}

Deneme formu, 2017-2018 eğitim öğretim yılı Diyarbakır ili merkez ilçelerine bağlı ilkokullarda görev yapan sınıf öğretmenleriyle gerçekleştirilmiştir. Uygulama sürecinde ölçme aracı formları araştırmacıların gözetiminde okullara bırakılmıştır. Ancak araştırmada katılımcı gönüllülü̈̆̈ü esas 
alındığından, sınıf öğretmenleri tarafından tamamlanmış olan 471 adet form elde edilmiştir. Elde edilen 471 form ön incelemeye tabii tutulmuş ve eksik doldurulduğu tespit edilen sekiz adet form çalışma kapsamının dışında tutulmuştur. Sınıf öğretmenlerinden elde edilen toplam 463 adet form numaralandırılıp veri dosyasına aktarılmış ve güvenirlik geçerlik çalışmaları yapılmıştır.

\section{Verilerin analizi}

Deneme formu aracılığıyla elde edilen veriler ölçeğin geçerlik ve güvenirlik çalışmaları için kullanılmıştır. Uygulama neticesinde elde edilen veri seti öncelikle seçkisiz olarak ikiye ayrılmış yarısında açımlayıcı faktör analizi diğer yarısında ise doğrulayıcı faktör analizi yapılmıştır. Yeni bir ölçek geliştirme sürecinde açımlayıcı ve doğrulayıcı faktör analizi için geniş bir örneklem büyüklüğüne ulaşıp elde dilen örneklemin yarısında açımlayıcı ve diğer yarısında doğrulayıcı faktör analizi yapmak tercih edilen ve önerilen bir yöntem olarak kabul görmektedir (Worthington ve Whittaker, 2006). Bu durumda açımlayıcı faktör analizi için veri setindeki ilk 232, doğrulayıcı faktör analizi için sonraki 231 sınıf öğretmeninden elde edilen veriler kullanılmıştır.

Faktör analizi için gerekli örneklem büyüklüğüne ilişkin alanyazın incelendiğinde bu konuda farklı görüsslerin olduğu görülmektedir (Pallant, 2005). Örneğin Tabachnick ve Fidell (2001) faktör analizi için örneklem büyüklüğünün en az 150, Büyüköztürk (2002) ise güçlü ve net faktörlerin bulunması ve değişken sayısının fazla olması durumunda 100 ile 200 arasında bir örneklem büyüklügünün yeterli olduğunu belirtmiştir. Bu görüşlerden hareketle faktör analizi için kullanılan örneklem büyüklüğ̈nün $(\mathrm{N}=232)$ güvenirlik ve geçerlik çalışmalarının yapılabilmesi için uygun olduğu kanaatine varılmıştır.

\section{Bulgular}

Bu bölümde ölçeğin geçerlik, güvenirlik ve madde analizlerine ilişkin bulgulara yer verilmiştir.

\section{Geçerliğe ilişkin bulgular}

Ölçeğin geçerlik çalışması için öncelikle ilgili alanyazın dikkatlice tarandıktan sonra madde yazımına geçilmiş ve yazılan maddeler uzman görüşüne sunulduktan sonra görünüş ve kapsam geçerliğine bakılmıştır. Kapsam geçerliği, ölçek maddesi ve soruları gibi görünür değişkenlerin asıl ölçmeyi hedeflediği başarı, tutum ve algı gibi gizil kavramları ölçmeye uygun olup olmadığını belirleme ile ilgiliyken (Muijs, 2004) görünüş geçerliği ise bir ölçme aracının ölçmek istediği bir yapıyı ne derece ölçebildiğiyle ilgilidir. Bilimsel çalışmalarda kapsam ve görünüş̧ geçerliği için uzman görüşüne başvurulması (Balc1, 2011) gerektiği belirtilmektedir. Ölçeğin kapsam ve görünüş geçerliğini belirlemek için uzman görüşüne başvurulmuş ve yenilikçi pedagoji uygulamalarını açıklayan kısa bir alanyazın derlemesi ile ön uygulama için hazır hale getirilen ölçeğin bir nüshası bir dil eğitimcisi, bir ölçme ve değerlendirme uzmanı ve eğitim programları ve öğretim alanındaki üç uzmanın incelemesine sunulmuştur. Uzmanlardan gelen dönütler neticesinde Yenilikçi Pedagoji Uygulamaları Ölçeğinin öğretmenlerin yenilikçi pedagoji uygulamalarını ölçebilecek görünüş ve kapsama sahip olduğu kanısına varılmıştır.

Ölçeğin geçerlik çalışmasının ikinci aşamasında yapı geçerliği incelenmiştir. Yapı geçerliğini sağlamak için açımlaycı faktör analizi (AFA) ve doğrulayıcı faktör analizi (DFA) yapılmıştır. Faktör analizi bir dizi değişken üzerindeki ölçümlerde incelenen değişkenler arasındaki ilişkileri belirlemek için gerekli faktör yapılarının sayısı ve doğası hakkında bilgi vermeyi amaçlayan bir analiz türüdür (Comrey ve Lee, 2013). Faktor analizi yapılmadan önce veri seti öncelikle normallik açısından test edilmiştir. Bu amaçla veri setinin basıklık (kurtosis) ve çarpıklık (skewness) değerleri normallik açısından incelenmiştir. Bir veri setinin normallik açısından değerlendirilmesinde çarpıklık ve basıklık değerlerinin kendi standart hata değerlerine bölünmesiyle elde edilen z puanına bakılır (Kim, 2013) ve elde edilen z puanının $+1,96$ ile -1,96 arasında olması, veri setinin normal dağılım gösterdiğini ifade eder (Can, 2013). Çarpıklık ve basıklık değerlerinin standart hatalarına bölümü sonucunda elde edilen $\mathrm{Z}$ puanlarına bakıldığında ise çarpıklık $\mathrm{z}$ değerinin $-1,18$ ve basıklı $\mathrm{z}$ değerinin 0,15 şeklinde olduğu ve veri setinin normal 
dağılım şartını sağladığı gözlenmiştir. Daha sonra ön uygulamadan elde edilen verilerin faktör analizi yapmaya uygun olup olmadığını test etmek amacıyla Kaiser-Meyer-Olkin (KMO) ve Barlett küresellik testi kullanılmıştır. Kaiser-Meyer-Olkin (KMO) değerinin 0,60'tan büyük olması söz konusu veri setinin faktör analizine uygun olduğu anlamına gelmekte ve bu değerin yüksek değer aldıkça her bir değişkenin diğer değişkenler tarafından mükemmel bir şekilde tahmin edilebileceğini varsaymaktadır (Büyüköztürk, 2007). Ayrıca bir ki-kare istatistiği olan Bartlett küresellik testi sonuçlarının 0,05'ten küçük olması veri setinin faktör analizine uygun olduğunu göstermektedir (Yurdugül, 2005).Yenilikçi Pedagoji Ölçeğinin Kaiser-Meyer-Olkin (KMO) ve Barlett küresellik testi sonuçlarına bakıldığında, Kaiser-Meyer-Olkin (KMO) değerinin 0,92 ve bu değerin 0,60 değerinden oldukça büyük olduğu böylece örneklem büyüklüğünün faktör analizi için "mükemmel" derecede uygun olduğu sonucuna ulaşılmıştır (Büyüköztürk, 2007). Ayrıca, Bartlett Küresellik Testi sonucu incelendiğinde ki-kare değerinin $\left(\mathrm{X}_{(1176)}^{2}=6538,318 ; \mathrm{p}<0,05\right) 0,05$ 'ten küçük olması verilerin çok değişkenli normal dağılımdan geldiğini göstererek faktör analizi uygulamak için normal dağılım koşulunun sağlandığı saptanmiştır.

\section{Faktör sayısının belirlenmesi}

Açımlayıcı faktör analizinde ölçekte yer alacak maddeleri belirlemek için madde toplam korelasyon değerinin en az 0,30 ve madde öz değerinin 1 olmasına dikkat edilmiştir (Büyüköztürk, 2012). Ölçekte yer alan maddelerin madde toplam korelasyon değerleri incelenmiş ve 22. 28. ve 46. maddeler 0,30'un altında yük değeri gösterdiği için ölçekten tek tek çıkarılmış ve her bir madde çıkarma işleminden sonra tekrar faktör analizi yapılmıştır. Ölçek faktör sayısının belirlenmesinde yamaç birikinti testine bakılmıştır. Yamaç birikinti testinde faktörlerin öz değerlerinin çizimle bir eğri üzerinde gösterilip eğrinin yönünün değişip yatay düzleme geldiği noktaya kadar eğri incelenir (Pallant, 2005) ve faktör sayısı art arda gelen faktörlerdeki özdeğer büyüklüğüne (bilgi miktarına) bakılarak belirlenir. Yamaç birikinti testi sonucunda oluşan grafikte ölçeğin daha büyük özdeğere sahip olan faktörleri dikey bölümde gösterilirken daha küçük özdeğere sahip faktörler ise yatay düzlemde gösterilir (Devellis, 2014).Yenilikçi pedagoji ölçeğinin yamaç birikinti testi sonucunda elde edilen yı̆̆ılma grafiği Şekil 1.'de gösterilmiştir.

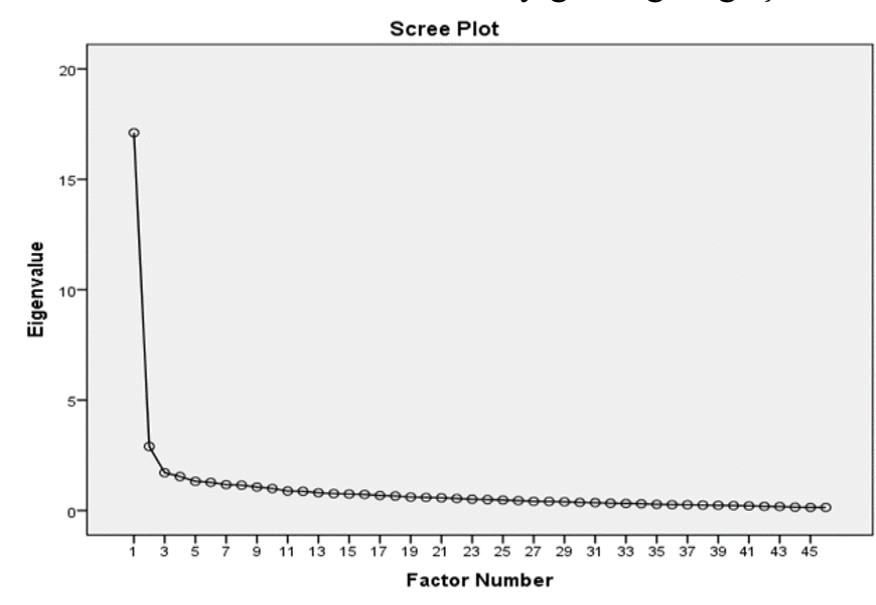

Şekil 1. Öğretmenler için Yenilikçi Pedagoji Uygulamaları Ölçeğinin yamaç birikinti testine göre maddelerin yığılma grafiğgi.

Öğretmenler İçin Yenilikçi Pedagoji Ölçeği yamaç birikinti testi sonucuna göre değerlendirildiğinde, özdeğeri 1'in üzerinde olan iki boyutun oluştuğu görülmektedir. Ancak ölçeğin faktör yapısının belirlenmesinde özdeğerin 1'den büyük olma kriteri, tek başına yeterli görülmemektedir. Bu durumda Lord (1980, akt., Hattie, 1985) birinci ve ikinci en büyük özdeğere sahip boyutlar arasındaki orana bakılması ve ikinci faktör yapısının özdeğeri ile geriye kalan diğer yapıların özdeğeri arasında çok fark olmaması gerektiğini belirtmektedir. Öğretmenler için Yenilikçi Pedagoji Ölçeğinin yamaç birikinti testi sonucuna bakıldığında birinci ve ikinci faktör yapısının özdeğeri arasında üçe yakın bir oran farkı bulunduğu ve ikinci faktör yapısının 
özdeğerinin ise geriye kalan yapıların özdeğerine yakın değerde olduğu görülmektedir. $\mathrm{Bu}$ durumdan hareketle Öğretmenler İçin Yenilikçi Pedagoji Uygulamaları Ölçeğinin toplam varyansının \%36,24'ünü açıklayan tek faktör altında toplandığı ve tek boyuttan oluştuğu sonucuna ulaşılmıştır. Tek boyuttan oluşan maddelerin faktör yükleri Tablo 3'de yer almaktadır.

Tablo 3

Öğretmenler İçin Yenilikçi Pedagoji Uygulamaları Ölçeğinin Faktör Analizi Sonuçları

\begin{tabular}{cccccc}
\hline MaddeNo & Faktör Yükü & Madde No & Faktör Yükü & Madde No & Faktör Yükü \\
\hline M1 & 0,59 & M17 & 0,63 & M34 & 0,56 \\
\hline M2 & 0,64 & M18 & 0,65 & M35 & 0,68 \\
\hline M3 & 0,50 & M19 & 0,66 & M36 & 0,58 \\
\hline M4 & 0,63 & M20 & 0,47 & M37 & 0,63 \\
\hline M5 & 0,59 & M21 & 0,62 & M38 & 0,68 \\
\hline M6 & 0,59 & M23 & 0,65 & M39 & 0,68 \\
\hline M7 & 0,66 & M24 & 0,68 & M40 & 0,50 \\
\hline M8 & 0,59 & M25 & 0,42 & M41 & 0,57 \\
\hline M9 & 0,65 & M26 & 0,60 & M42 & 0,52 \\
\hline M10 & 0,45 & M27 & 0,55 & M43 & 0,54 \\
\hline M11 & 0,62 & M29 & 0,41 & M44 & 0,50 \\
\hline M12 & 0,63 & M30 & 0,58 & M45 & 0,65 \\
\hline M13 & 0,60 & M31 & 0,59 & M47 & 0,72 \\
\hline M14 & 0,65 & M32 & 0,64 & M48 & 0,53 \\
\hline M15 & 0,67 & M33 & 0,68 & M49 & 0,66 \\
\hline M16 & 0,61 & & & & \\
\hline
\end{tabular}

Tablo 3 incelediğinde, yenilikçi pedagoji uygulamaları ölçeğinin tek boyut altında toplanmış 46 maddeden oluştuğu, maddelerin faktör yüklerinin 0,41 ile 0,72 arasında değiştiği ve 0,32 kabul düzeyini geçtiği gözlenmektedir. Ayrıca sosyal bilimlerde geliştirilen ölçek geliştirme çalışmalarında tek faktörlü desenlerde açılanan varyansın $\% 30$ ve üzerinde olması yeterli görüldüğünden (Çokluk, Şekercioğlu ve Büyüköztürk, 2014) ölçeğin tek faktörü ölçeğin toplam varyansının \%36'sını açıklayarak açıklanan toplam varyans değerini de karşıladığı görülmektedir.

Öğretmenler için Yenilikçi Pedaogoji Uygulamaları Ölçeğinin tek faktörlü deseninin test edilmesi amacıyla ikinci adımda, önceden belirlenmiş ya da kurgulanmış bir yapıya ilişkin istatistiksel kanıtlar sağlayan bir analiz tekniği olan (Brown, 2015) doğrulayıcı faktör analizi (DFA) toplanan verilerin diğer yarısına $(\mathrm{N}=231)$ uygulanmış ve faktör analiz diyagramı Şekil 2'de gösterilmiştir.

DFA analizlerinin gerçekleştirilmesinde "maksimum olabilirlik kestirim yönteminden" faydalanılmıştır. Tek boyutlu bir yapı olan ölçeğin DFA analizi sonucunda bütün maddelerin ilgili boyutta yük değeri aldığı ve faktör yük değerlerinin 0,39 ile 0,71 aralığında yer aldığ 1 saptanmış ve bu değerlerin maddenin ilgili yapıyı temsil etmesi için yeterli olduğu sonucuna ulaşılmıştır. Ayrıca diyagramda değişkenlerin $\mathrm{t}$ değerlerine bakıldığında kırmızı renkte herhangi bir değere rastlanılmamıştır ve bu durum da örtük değişkenler arası ilişkinin anlamlı olduğunu göstermektedir. Faktör yük değerlerinin yanı sıra genel model-veri uyumuna işaret eden bir takım uyum indekslerinden de faydalanılmıştır. Model uyumunun değerlendirilmesinde çeşitli indeksler mevcuttur ve her bir indeks model uyumuna ilişkin farklı bilgiler sağlamaktadır. Bu indeksler "mutlak uyum (absolute fit)", "parsimony düzeltme (parsimony correction)", ve "karşılaştırmalı uyum (comparative fit)" olmak üzere üç kategoride ele alınmaktadır. Model uyumunun değerlendirilmesinde her bir kategoriden en az bir indeksin raporlanması ise uygun görülmektedir (Brown, 2015). Bu ölçeğin uyarlama çalışmasında mutlak uyum kategorisinde yer alan ki-kare, parsimony düzeltme kategorisinde yer alan RMSEA ve karşılaştırmalı uyum kategorisinde yer alan karşılaştırmalı uyum indeksi (CFI), normlaştırılmış uyum indeksi (NFI) ve normlaştırılmamış uyum indeksi (NNFI)'inden faydalanılmıştır. Ölçeğin genel uyumuna ilişkin bu indeksler Tablo 4'de sunulmuştur. 
Öğretmenler İçin Yenilikçi Pedagoji Uygulamaları Ölçeği: Geçerlik ve Güvenirlik Çalışması

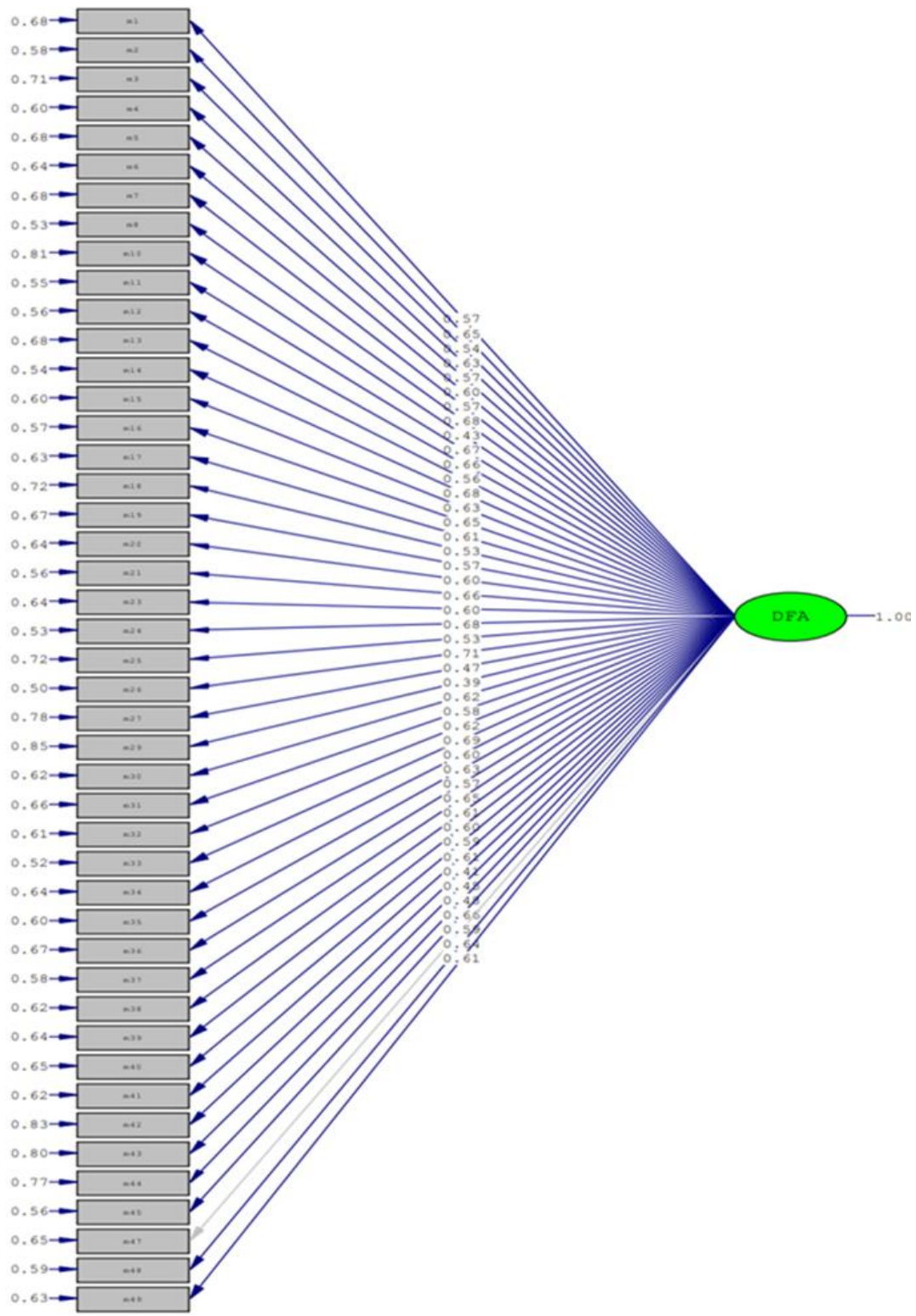

Şekil 2. Öğretmenler için Yenilikçi Pedagoji Uygulamaları Ölçeğinin Doğrulayıcı Faktör Analizi (DFA) Diyagramı

Tablo 4

Öğretmenler İçin Yenilikçi Pedagoji Uygulamaları Ölçeğinin DFA Sonucunda Elde Edilen Uyum Indeksleri

\begin{tabular}{lccccccccccc}
\hline Ki kare & Sd & $\begin{array}{c}\text { Kikare } \\
\text { /sd }\end{array}$ & RMSEA & CFI & NFI & NNFI & PNFI & GFI & AGFI & IFI & SRMR \\
\hline 2237,47 & 945 & 2,37 & 0,076 & 0,96 & 0,93 & 0,95 & 0,88 & 0,65 & 0,62 & 0,96 & 0,07 \\
\hline
\end{tabular}

Tablo 4'e göre ki-karenin serbestlik derecesine bölümüne ilişkin değerin 2,84'ten küçük olduğu görülmektedir. Bu değer mükemmel uyuma işaret etmektedir (Kline, 2005). RMSEA değeri incelendiğinde bu değerin 0,076 olduğu ve iyi uyuma işaret ettiği görülmektedir (Brown, 2006; 
Jöreskog ve Sörbom, 1996). Son olarak karşılaştırmalı uyum indekslerinden CFI, IFI ve NNFI değerlerinin mükemmel uyuma; NFI indeksinin ise iyi uyuma işaret ettiği görülmektedir (Hooper, Coughlan ve Mullen, 2008). SRMR ise kabul edilebilir uyuma işaret etmektedir (SchermellehEngel, Moosbrugger ve Müller, 2003). Üç farklı uyum kategorisinde yer alan uyum indekslerine göre modelin veriye uyum sağladığı ve tek boyutlu yapının doğrulandığı sonucuna ulaşılmıştır.

\section{Güvenirliğe ilișkin bulgular}

Ölçek geliştirme sürecinde ölçeğin güvenilir olması önem arz eden bir husustur ve güvenirliği belirlemek için kullanılabilecek farklı yöntemler bulunmaktadır (Pallant, 2016). Bu yöntemlerden en sık tercih edileni Cronbach alfa iç tutarlılık katsayısıdır (Devellis, 2014). Öğretmenler İçin Yenilikçi Pedaogoji Uygulamaları Ölçeğinin güvenirlik analizinde Cronbach alfa iç tutarlılık katsayısı hesaplanmıştır. Cronbach's Alpha iç tutarlılık katsayısı, bir testteki tüm öğelerin aynı kavramı veya yapıyı ne derecede ölçtügünü ve dolayısıyla test içindeki öğelerin birbirleriyle olan ilişkisini ifade eder. 0 ile 1 arasında değer alan ve alt sınır değeri bulunmayan Cronbach's alpha iç tutarlılık katsayısının 1'e yaklaştıkça ölçek maddelerinin iç tutarlılı̆̆ının arttığından güvenirliğin arttığ 1 kabul edilmektedir (Gliem ve Gliem, 2003; Tavakol ve Dennick, 201). Tek boyut altına toplanmış 46 maddeden oluşan Öğretmenler İçin Yenilikçi Pedaogoji Uygulamaları Ölçeği'nin Cronbach alpha iç tutarlılık katsayısının 0,95 olarak hesaplandığı ve ölçeğin yüksek düzeyde iç tutarllğa ve dolayısıyla yüksek düzeyde güvenirliğe sahip olduğu söylenebilir.

\section{Madde analizi}

Ölçek maddelerinin ayırt ediciliklerini test etmek amacıyla madde analizi yapılmıştır. Likert, madde analizi yapılabilmesi için "korelasyonlara dayalı analiz" ve "iç tutarlık ölçütüne dayalı analiz" olmak üzere iki tür madde analizinden söz etmektedir (Tezbaşaran, 2004). Bu amaçla, ölçeğin madde analizlerinin yapılabilmesi için korelasyona dayalı analiz yöntemi kullanılmış ve ölçek maddelerinin toplam korelasyonuna bakılmıştır. Devellis (2014) maddeler arasında korelasyonun yüksek olmasının güvenirliği arttıracağını bu yüzden de madde toplam korelasyonunun ne kadar yüksek olursa o kadar iyi olacağını ifade etmiştir. Ebel (1995) ise madde toplam korelasyonuna ilişkin aralık değerler belirterek madde toplam korelasyon katsayılarının 0,20 'nin altında olması durumunda maddenin çıkarılması gerektiğini, $0,20-0,30$ arasındaysa maddenin düzeltilmesi gerektiğini ve 0,30 - 0,40 arasındaysa iyi ve 0,40 ve üzerindeyse çok iyi olarak nitelendirilebileceğini belirtmiştir. Yapılan analizler sonucunda Öğretmenler İçin Yenilikçi Pedagoji Ölçeğinin madde toplam korelasyonlarının 0,40 ile 0,68 arasında değiştiği tespit edilmiştir. Ayrıca \% 27'lik alt ve üst grup puanları arasındaki fark bağımsız örneklemler için t-testi kullanılarak da test edilmiştir. Her bir madde için yapılan bağımsız örneklemler için ttesti sonucunda alt ve üst gruplar arasında anlamlı fark bulunmuştur. Buna göre ölçekte yer alan maddelerin Ebel'in (1995) sınıflandırmasına göre "çok iyi” düzeyinde ve yüksek ayırt ediciliğe sahip olduğu söylenebilir.

\section{Tartışma, Sonuç ve Öneriler}

$\mathrm{Bu}$ çalışmada öğretmenlerin yenilikçi pedagojiyi ne düzeyde uyguladıklarını tespit etmek amacıyla beşli Likert tipi “Öğretmenler için Yenilikçi Pedaogoji Uygulamaları Ölçeği” (ÖYPUÖ) geliştirilmiştir. İlkokullarda görev yapan toplam 463 sınıf öğretmenine uygulanarak geliştirilen ölçek 46 madde ve tek boyutlu faktör yapısı göstermiş ve tek boyutlu faktör yapısı doğrulayıcı faktör analizi aracılığıyla herhangi bir modifikasyon yapılmadan doğrulanmıştır. Ölçeğin iç tutarlılık güvenirlik katsayısı ise 0,95 olarak hesaplanmıştır. Öğretmenler için Yenilikçi Pedagoji Uygulamaları Ölçeği'nde ters madde bulunmayıp tüm maddeler pozitif olarak puanlanmaktadır ve ölçekten alınan yüksek bir puanın öğretmenin sınıf içinde yenilikçi uygulamaları sıklıkla kullandığını ifade ederken, düşük bir puanın ise öğretmenin sınıf içinde yenilikçi uygulamaları hiç veya nadiren kullandığını ifade ettiği anlaşılmaktadır.

$\mathrm{Bu}$ alanda yapılan ölçek geliştirme çalışmalarına bakıldığında öğretmenlerin yenilikçilik ve mesleki yenilikçilik düzeylerini belirlemeye yönelik ölçek geliştirme çalışmalarının gerçekleştirildiği (Kocasaraç ve Karataş, 2018; Altıntaş-Yüksel ve Gelişli, 2018) saptanmıştır. Kocasaraç ve Karataş (2018) geliştirdikleri "Yenilikçi Öğretmen Özellikleri Ölçeği”, "yeniliklere açık öğretmen", "bilişim teknolojilerine açık öğretmen", "öğrenmeye açık öğretmen" ve 
Öğretmenler İçin Yenilikçi Pedagoji Uygulamaları Ölçeği: Geçerlik ve Güvenirlik Çalışması

"gelişime ve işbirliğine açık öğretmen" olmak üzere dört faktörlü ve toplam varyansın \% 45 'ni açıklayan bir yapıya ulaşmışlardır. Altıntaş-Yüksel ve Gelişli (2018) de geliştirdikleri 'Sınıf Öğretmenlerinin Mesleki Yenilikçilik Ölçeği’”nde öğrenmede yenilikçi, meslekte yenilikçi ve yeniliğe direnç olmak üzere toplam varyansın \% 40'nı açıklayan bir yapıya ulaşmışlardır. Çalışma ortamında yenilikçi davranışları çalışmak karmaşık ve zor bir iştir çünkü araştırmacılar çalışma ortamındaki algılarla sınırlı kaldığından ölçütün onaylanması genellikle zordur. Ancak yenilikçilik birçok çalışma alanına girdiğinden bu tür çalışmalara olan ihtiyaç da artmaktadır (Scott ve Bruce, 1994). Ayrıca ilgili alanyazında örneklem büyüklügü ve madde sayısı gibi faktörlerin faktör analizi sonuçları ve boyut sayısında etkili olduğu (Osborne ve Costello, 2004) düşünüldüğünde her üç ölçekte de farklı faktör sayısının çıkması beklenen bir sonuç gibi görünmektedir. Bununla birlikte yenilikçilik kavramının bilimsel bir çalışma alanı olarak uzun süreli bir geçmişe sahip iken (Rogers, 2002) yenilikçi pedagoji kavramı ilgili alan yazına yeni kazandırılmış bir kavram olup bu alanda yapılan kuramsal çalışmalarda yenilikçi bir eğitimci ve yenilikçi öğrenme öğretme sürecinin bilimsel olarak çalışılmasını ifade etmektedir (What is Innovative Pedagogy, 2011). Bu açıdan bakıldığında Kocasaraç ve Karataş (2018) ile AltıntaşYüksel ve Gelişli (2018) tarafından geliştirilen ölçme araçlarının yenilikçi eğitimci boyutuna yönelik olduğu görülmektedir. Öğretmenler için Yenilikçi Pedagoji Uygulamaları Ölçeği ise yenilikçi öğrenme-öğretme sürecine yönelik bir ölçme aracı olarak geliştirilmiştir. Sonuç olarak Öğretmenler için Yenilikçi Pedagoji Uygulamaları Ölçeği'nin alanyazına geçerliği ve güvenirliği yüksek bir ölçme aracı kazandırdığı düşünülmektedir. Bu ölçek kullanılarak farklı okul ve kademelerde görev yapan öğretmenlerin yenilikçi pedagoji uygulamalarına ilişkin görüşleri incelenebilir ve öğretmenlerin yenilikçi pedagoji uygulamaları farklı değişkenler açısından test edilebilir. Ayrıca, öğretmenlerin yenilikçi pedagoji uygulamalarına etki eden faktörler ve durumlar bu ölçek yardımıyla ortaya çıkarılabilir. Yine öğrencilerin gözünden öğretmenlerin yenilikçi pedagoji uygulamalarını incelemeyi amaçlayan ölçme araçları geliştirilebilir.

\section{Katkı Sunanlar}

Bu çalışma, Dicle Üniversitesi Bilimsel Araştırmalar Merkezi (DÜBAP) tarafından ZGEF.18.014 numaralı proje ile desteklenmiştir. Desteklerinden ötürü DÜBAPa teşekkür ederiz.

\section{Etik Kurul Onay Bilgileri}

Bu çalışma, Dicle Üniversitesi Eğitim Bilimleri Etik Kurulu'nun 24.04.2018 tarih ve 37803 sayılı kararı ile araştırma ve yayın etiğine uygun olarak gerçekleştirilmiştir.

\section{Kaynaklar}

Akyüz, H. (1991). Eğitim sosyolojisinin temel kavram ve alanları üzerine bir araştırma. İstanbul: MEB Yayınları.

Altıntaş-Yüksel, E. ve Gelişli, Y. (2018). Sınıf öğretmenlerinin mesleki yenilikçilik eğilimleri ölçeği: Geliştirilmesi, geçerliliği ve güvenilirliği, Ulakbilge, 6(26), 821-839.

Balc1, A. (2011). Sosyal bilimlerde araştirma: Yöntem, teknik ve ilkeler. Ankara: Pegem Akademi.

Beetham, H., ve Sharpe, R. (2013). An introduction to rethinking pedagogy. Rethinking Pedagogy for a Digital Age: Designing for 21 st Century Learning. New York: Routledge.

Bennett, S., Maton, K. ve Kervin, L. (2008). The 'Digital Natives' debate: A critical review of the evidence. British Journal of Educational Technology,39(5), 775-786.

Brown, T. A. (2015). The common factor model and exploratory factor analysis. In D. A. Kenny, \& T. D. Little (Eds.), Confirmatory factor analysis for applied research (pp. 12-37). New York: The Guilford Press.

Büyüköztürk, Ş. (2002). Faktör analizi: Temel kavramlar ve ölçek geliştirmede kullanımı. Kuram ve Uygulamada Ĕ̈itim Yönetimi, 32(32), 470-483.

Büyüköztürk, Ş. (2007). Veri analizi el kitabi (7. bask1). Ankara: Pegem Akademi.

Büyüköztürk, Ş. (2012). Sosyal bilimler için veri analizi el kitabi (16. bask1). Ankara: Pegem Akademi. 
Süer ve Oral

Büyüköztürk, Ş., Çakmak, E. K., Akgün, Ö. E., Karadeniz, Ş. ve Demirel, F. (2013). Bilimsel araştirma yöntemleri. Ankara: Pegem Akademi.

Can, A. (2013). Bilimsel araştırma sürecinde nicel veri analizi. Ankara: Pegem Akademi.

Comrey, A. L., \& Lee, H. B. (2013). A first course in factor analysis ( $2^{\text {nd }}$ edition). Hillsdale, NJ: Lawrence Erlbaum Associates, Inc.

Çimen, İ. ve Yücel, C. (2017).Yenilikçi davranış ölçeği (YDÖ). Türk kültürüne uyarlama çalışması. Cumhuriyet International Journal of Education.6(3), 365-381.

Çokluk, Ö., Şekercioğlu, G. ve Büyüköztürk, Ş. (2014). Sosyal bilimler için çok değişkenli istatistik SPSS ve Lisrel uygulamalart. Ankara: Pegem Akademi.

Dawe, S. (2004). Vocational education and training and innovation. Research readings. Stational arcade. Australia: National Centre for Vocational Education Research Ltd.

Devellis, F. (2014). Ölçek geliştirme: Kuram ve uygulama (T. Totan, çev). Ankara: Nobel Yayıncilik.

Ebel, R. L. (1995). Measuring educational achievement. New Jersey: Prentice-Hall.

Edwards, S., \& Bone, J. (2012). Integrating peer assisted learning and e-learning: Using innovative pedagogies to support learning and teaching in higher education settings. Australian Journal of Teacher Education, 37(5), 1-12.

Gliem, J. A., \& Gliem, R. R. (2003, October). Calculating, interpreting, and reporting cronbach's alpha reliability coefficient for likert-type scales. Paper presented at Midwest Researchto-Practice Conference in Adult, Continuing, and Community Education. Columbus, OH, USA.

Hattie, J. (1985). Methodology review: Assessing unidimensionality of tests and items. Applied Psychological Measurement, 9(2), 139-164.

Hooper, D., Coughlan, J., \& Mullen, M. (2008). Structural equation modelling: Guidelines for determining model fit. Electron J Bus Res Methods 6, 53-60.

Hughes, J. (2005). The role of teacher knowledge and learning experiences in forming technology-1ntegrated pedagogy. Journal of Technology and Teacher Education, 13(2), 277-301.

Hurt, H. T., Joseph, K., \& Cook, C. D. (1977). Scales for the measurement of innovativeness. Human Communication Research, 4(1), 58-65. doi: 10.1111/j.1468-2958.1977.tb00597.x

Jirasatjanukul, K., \& Jeerungsuwan, N. (2018). The design of an instructional model based on connectivism and constructivism to create innovation in real world experience. International Education Studies, 11(3), 12-17.

Jöreskog, K. G., \& Sörbom, D. (1996). LISREL 8 User's reference guide. Uppsala, Sweden: Scientific Software International.

Karadoğan, A. (2019). Z kuşağı ve öğretmenlik mesleği. A ̆ğr İbrahim Çeçen Üniversitesi Sosyal Bilimler Enstitüsü Dergisi, 5(2), 9-42.

Karataş, K. (2020). Öğretmenlik mesleğine kuramsal bir bakış. Electronic Journal of Education Sciences, 9(17), 39-56.

Katitia, D. M. O. (2015). Teacher education preparation program for the 21 st century. Which way forward for Kenya? Journal of Education and Practice, 6(24), 57-63.

Kavalcı, K. ve Ünal, S. (2016). Y ve z kuşaklarının öğrenme stilleri ve tüketici karar verme tarzları açısından karşılaştırılması. Journal of Graduate School of Social Sciences, 20(3), 10331050 .

Kılıçer, K. ve Odabaşı, H.F. (2010) Bireysel yenilikçilik ölçeği (BYÖ): Türkçeye uyarlama, geçerlik ve güvenirlik çalışması. Hacettepe Üniversitesi Eğitim Fakültesi Dergisi,38, 150-164.

Kim, H. Y. (2013). Statistical notes for clinical researchers: assessing normal distribution (2) using skewness and kurtosis. Restorative Dentistry \& Endodontics, 38(1), 52-54.

Knowles, M. S. (1970). The modern practice of adult education (Vol. 41). New York: New York Association Press.

Kocasaraç, H. ve Karataş, H. (2018). Yenilikçi öğretmen özellikleri: Bir ölçek geliştirme çalışması. Uşak Üniversitesi Eğitim Araştırmaları Dergisi, 4(1), 34-57. 
Öğretmenler İçin Yenilikçi Pedagoji Uygulamaları Ölçeği: Geçerlik ve Güvenirlik Çalışması

Konokman, G. Y., Yokuş, G. ve Yelken, T. Y. (2016).Yenilikçi materyal tasarlamanın sınıf öğretmeni adaylarının yenilikçilik düzeylerine etkisi. Bartın Üniversitesi Eğitim Fakültesi Dergisi, 5(3), 857-878.

McCrindle, M., \& Wolfinger, E. (2009). The ABC of XYZ: Understanding the global generations. Australia, Sydney: University of New South Wales Press.

Muijs, D. (2004). Doing quantitative research in education with SPSS. Thousand Oaks, California: SAGE Publications Inc.

Osborne, J. W., \& Costello, A. B. (2004). Sample size and subject to item ratio in principal components analysis. Practical assessment, research \& evaluation, 9(11),1-9.

Pallant, J. (2005). SPSS survival manual: A step by step guide to data analysis using spss for windows (Version 12). Buckingham: Open University Press.

Pallant, J. (2016). SPSS kullanma kılavuzu: SPSS ile Adım Adım Veri Analizi (S. Balc1 ve B. Ahi, Çev). Ankara: Anı Yayıncılık.

Prachagool, V., Nuangchalerm, P., Subramaniam, G., \& Dostal, J. (2016). Pedagogical decision making through the lens of teacher preparation program. Online Submission, 4(1), 41-52.

Redding, S., Twyman, J. S., \& Murphy, M. (2013). What is an innovation in learning? In M. Murphy, S. Redding, \& J. Twyman (Eds.), Handbook on innovations in learning (pp. 314). Philadelphia, PA: Center on Innovations in Learning, Temple University; Charlotte, NC: Information Age Publishing. Retrieved from http://www.centeril.org/

Rogers, E. M. (2002). Diffusion of preventive innovations. Addictive Behaviors, 27(6), 989-993. Rusdiana, A. (2014). Konsep Inovasi Pendidikan. Bandung: CV Pustaka Setia.

Salmon, G. (2005). Flying not flapping: A strategic framework for e-learning and pedagogical innovation in higher education institutions. ALT-J, 13(3), 201-218.

Scott, S. G., \& Bruce, R. A. (1994). Determinants of innovative behavior: A path model of individual innovation in the workplace. Academy of Management Journal, 37(3), 580607.

Schermelleh-Engel, K., Moosbrugger, H., \& Müller, H. (2003). Evaluating the fit of structural equation models: Tests of significance and descriptive goodness-of-fit measures. Methods of Psychological Research Online, 8(2), 23-74.

Stukalenko, N. M., Zhakhina, B. B., Kukubaeva, A. K., Smagulova, N. K., \& Kazhibaeva, G. K. (2016). Studying innovation technologies in modern education. International Journal of Environmental and Science Education, 11(14), 6612-6617.

Tabachnick, B. G., \& Fidell, L. S. (2001). Using Multivariate Statistics (4th edition). New York: Harper Collins.

Tavakol, M., \& Dennick, R. (2011). Making sense of cronbach's alpha. International Journal of Medical Education, 2, 53-55.

Vikas, O. (2012). Innovation-centric teaching and learning processes in technical education. Journal of Modern Education Review, 2(2), 116-131.

What is Innovative Pedagogy? (2011, October). Retrieved from https://www.researchgate.net/ post/What_is_Innovative_Pedagogy2.

Wiersma, W. (1995). Research Methods in Education: An Introduction (6 $6^{\text {th }}$ edition). Boston: Allyn Bacon Inc.

Williamson, R. (2011). Digital literacy. Education Partnerships Inc. Retrieved from https://files.eric.ed.gov/fulltext/ED538315.pdf

Worthington, R., \& Whittaker, T. (2006). Scale development research: A content analysis and recommendations for best practices. Counseling Psychologist, 34, 806-838.

Tezbaşaran, A. A. (2004). Likert tipi ölçeklere madde seçmede geleneksel madde analizi tekniklerinin karşılaştırılması. Türk Psikoloji Dergisi, 19(54), 77-87.

Yurdugül, H. (2005). Faktör analizinde KMO ve Bartlett testleri neyi ölçer? Ankara: Hacettepe Üniversitesi Yayınları. http://yunus.hacettepe.edu.tr/ yurdugul/3/indir/Kuresellik.pdf. adresinden edinilmiştir. 


\section{Introduction}

\section{Extended Abstract}

The innovation theory in education has emerged as a new field in the study of scientific pedagogy as a process of innovation in the global economy, which is considered to be indispensable of today's co-operative world (Stukalenko, Zhakhina, Kukubaeva, Smagulova \& Kazhibaeva, 2016). Innovative pedagogy emphasizes the use of all possible technologies in the classroom within the learning-teaching process and approaches (Salmon, 2005). In this way, it enables the development of alternative practices in the learning-teaching environment (Edwards \& Bone, 2012) to help the implementation of student-centered approaches into education. Teachers have great responsibilities in maintaining an innovative educational approach as they play a key role in training individuals with the knowledge, skills and qualifications that the society needs (Prachagool, Nuangchalerm, Subramaniam, \& Dostál, 2016). For this reason, it is important that teachers manage the learning and teaching process in line with methods and techniques of the age we live in. In this context, the aim of this study is to develop a scale to determine the level of teachers' innovative pedagogical practices.

The related literature presents that studies on teachers' innovativeness have been frequently investigated via Individual Innovativeness Scale developed by Hurth, Joseph, and Cook (1977). This scale categorizes people according to their reaction to an innovation or the how long it takes them to adopt an innovation. This scale is useful for measuring the indivudual innovativenes of a person indeed; however, it fails to provide data on innovative practices of teachers in the educational environment. In addition, "Innovative Teacher Characteristics Scale" consisting of 53 items and four sub-dimensions was developed by Kocasaraç and Karataş (2018). The Classroom Teachers' Professional Innovation Scale consisting of 52 items and three sub-dimensions was developed by Altıntaş-Yüksel and Gelisli (2018). The scope of innovative pedagogy includes both the innovative teachers and innovative learning and teaching practices in the classroom (What is Innovative Pedagogy, 2011). In this context, as a scale measuring the innovative teaching practices of teachers in the classroom has not been found in the related literature, this study aims to develop a valid and reliable measurement tool to determine views of teachers about how often they use innovative pedagogical practices in their classrooms.

\section{Method}

This study aimed to develop a scale to determine the teachers' views towards innovative pedagogical practices. The study was conducted on the basis of survey design. The study group consisted of 463 classroom teachers, $45.4 \%$ of whom were female and $53.8 \%$ of whom were male working in the primary schools located in Diyarbakır in 2017-2018 academic year. In the process of scale development; first of all, item pool was established in line with the theoretical framework then the item pool was sent for experts opinion. After that necessary regulations were made and a draft scale was designed and applied to classroom teachers. The data obtained was split in two halves then validity and reliability analyses were carried on different halves. Finally, the reliability coefficient (Cronbach's alpha) was calculated and item analysis was performed.

\section{Results and Discussion}

In the first phase, the first half consisting 232 variables was tested with KMO and Barlett test to examine the data set for explanatory factor analysis. It was concluded that the data set met the requirement for applying exploratory factor analysis. Then factor analysis was performed with 50 items. The item total correlation values of the items in the scale were examined, and 2 items were omitted from the scale. In order to determine the factor numbers, the result of scree plot test was examined. The results of scree plot test showed that the innovative pedagogical practices scale for teachers was comprised of 46 items with single factor explaining $36.24 \%$ of total variance. Then, the confirmatory factor analysis was performed with the other half consisting of 231 variables. Innovative Pedagogical Practices Scale for Teachers consisting of 46 items with a single dimension and explaining $36 \%$ of the total variance was confirmed with CFA. The results 
of confirmatory factor analysis indicated perfect or good agreement with the following values: Standardized RMR compliance index was .08, CFI is .96, NFI is .93, NNFI is .95, and chisquare/df was 2.37. According to the fit indexes in three different compliance categories, it was concluded that the model complied with the data and the structure with single factor was confirmed. The Cronbach alpha consistency coefficient was .95. As a result, a reliable and valid "Innovative Pedagogical Practices Scale for Teachers" was developed.

In this study, a five-point Likert-type Innovative Pedagogical Practices Scale for Teachers (IPPST) was developed with the aim of determining teachers' level of innovative pedagogical practices. The scale was developed by applying draft form to 463 classroom teachers working in primary school. As a result, a valid and reliable scale consisting of 46 items with single factor explaining $36.24 \%$ of total variance was obtained. The obtained structure was verified without any modification by confirmatory factor analysis. The Cronbach-Alpha consistency coefficient was calculated as .95.

When the related literature in the field has been examined, it is determined that scale development studies are carried out to determine the innovativeness or professional innovativeness of teachers (Kocasaraç \& Karatas, 2018; Altıntas-Yüksel \& Gelisli, 2018). Since there are no studies performed to develop a scale to determine the teachers' views about how often they use innovative pedagogical practices in their classrooms in the literature, it is thought that this study contributes to the literature with a valid and reliable measurement tool. 


\section{Ek 1: Öğretmenler İçin Yenilikçi Pedagoji Uygulamaları Ölçeği}

\begin{tabular}{|c|c|c|c|c|c|c|}
\hline & $\begin{array}{l}\text { Aşağıda yer alan her bir maddeyi dikkatli bir şekilde okuduktan } \\
\text { sonra ilgili seçeneği }(\mathrm{X}) \text { işaretleyiniz. }\end{array}$ & 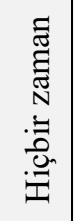 & 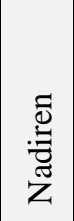 & 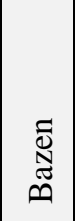 & $\begin{array}{l}\frac{y}{\bar{n}} \\
\frac{y}{\bar{n}}\end{array}$ & 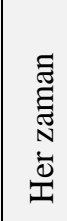 \\
\hline 1. & $\begin{array}{l}\text { Etkili bir öğrenme-öğretme süreci tasarlayabilmek için eğitim } \\
\text { teknolojilerinden aktif olarak faydalanırım. }\end{array}$ & & & & & \\
\hline 2. & $\begin{array}{l}\text { Öğrenme-öğretme sürecinde etkinlikler düzenlerken yeni fikirler } \\
\text { üretirim. }\end{array}$ & & & & & \\
\hline 3. & $\begin{array}{l}\text { Öğrenme-öğretme etkinliklerini mevcut teknolojik olanaklara yer } \\
\text { verecek şekilde planlarım. }\end{array}$ & & & & & \\
\hline 4. & $\begin{array}{l}\text { Öğrenme-öğretme sürecinde yeni öğretim teknikleri uygulamaya } \\
\text { çalışırım. }\end{array}$ & & & & & \\
\hline 5. & $\begin{array}{llll}\text { Öğrenme-öğretme } & \text { etkinliklerini } & \text { zenginleştirmek } & \text { amacıyla } \\
\text { teknolojiden yararlanırım. } & & \\
\end{array}$ & & & & & \\
\hline 6. & Eğitim ile ilgili yenilikleri takip ederim. & & & & & \\
\hline 7. & $\begin{array}{l}\text { Mevcut öğretim materyallerini teknolojinin } \\
\text { gereksinimlere cevap verecek şekilde geliştiririm. }\end{array}$ & & & & & \\
\hline 8. & Özgün öğrenme ortamları hazırlarım. & & & & & \\
\hline 9. & $\begin{array}{l}\text { Öğrenme-öğretme sürecini desteklemek amacıyla teknolojik } \\
\text { yenilikleri kullanırım. }\end{array}$ & & & & & \\
\hline 10. & $\begin{array}{l}\text { Meslektaşlarımın kuşku ile yaklaştığ } 1 \text { yenilikleri sınıfımda } \\
\text { uygularım. }\end{array}$ & & & & & \\
\hline 11. & Mesleki alan bilgimi geliştirmek için teknolojiden yararlanırım. & & & & & \\
\hline 12. & $\begin{array}{l}\text { Öğrenme-öğretme sürecini etkili kılabilecek özgün davranışlar } \\
\text { sergilerim. }\end{array}$ & & & & & \\
\hline 13. & $\begin{array}{llll}\begin{array}{l}\text { Teknolojik yeniliklerin okulumdaki } \\
\text { kullanılmasına öncülük ederim. }\end{array} & \text { sürecinde } \\
\end{array}$ & & & & & \\
\hline 14. & $\begin{array}{l}\begin{array}{l}\text { Öğrenme-öğretme sürecinde yenilikçi eğitim uygulamalarına } \\
\text { başvururum. }\end{array} \\
\text {. }\end{array}$ & & & & & \\
\hline 15. & $\begin{array}{l}\text { Sınıfta kullanıldığında derse katkı sağlayacak teknolojilerden } \\
\text { etkili bir şekilde yararlanabilmek için çaba sarf ederim. }\end{array}$ & & & & & \\
\hline 16. & $\begin{array}{l}\text { Sınıfımda karşılaştı̆ım sorunları yeni yöntemlerle çözmeye } \\
\text { çalışırım. }\end{array}$ & & & & & \\
\hline 17. & $\begin{array}{l}\text { Öğrenciyi derste aktif kılmak için teknolojik yeniliklerden } \\
\text { yararlanırım. }\end{array}$ & & & & & \\
\hline 18. & $\begin{array}{l}\begin{array}{l}\text { Meslektaşlarıma olumlu yönde katk1 sağlayacak yenilikler } \\
\text { geliştiririm. }\end{array} \\
\text {. }\end{array}$ & & & & & \\
\hline 19. & $\begin{array}{l}\text { Teknolojinin öğrenme-öğretme süreçlerine etkili bir şsekilde } \\
\text { entegrasyonu konusunda yeni fikirler üretirim. }\end{array}$ & & & & & \\
\hline 20. & Değişimlere kolaylıkla uyum sağlarım. & & & & & \\
\hline 21. & Uygun teknolojileri seçerek dersin içeriğini zenginleştiririm. & & & & & \\
\hline 22. & Öğretimin niteliğini geliştirici yeni fikirler tasarlarım. & & & & & \\
\hline 23. & $\begin{array}{l}\text { Öğrenme-öğretme sürecinde yaşanan ortak problemleri çözmek } \\
\text { için farklı yollar uygulamaya çalışırım. }\end{array}$ & & & & & \\
\hline 24. & Okulda herkesin ilgisini çekebilecek etkinlikler düşünürüm. & & & & & \\
\hline
\end{tabular}


Öğretmenler İçin Yenilikçi Pedagoji Uygulamaları Ölçeği: Geçerlik ve Güvenirlik Çalışması

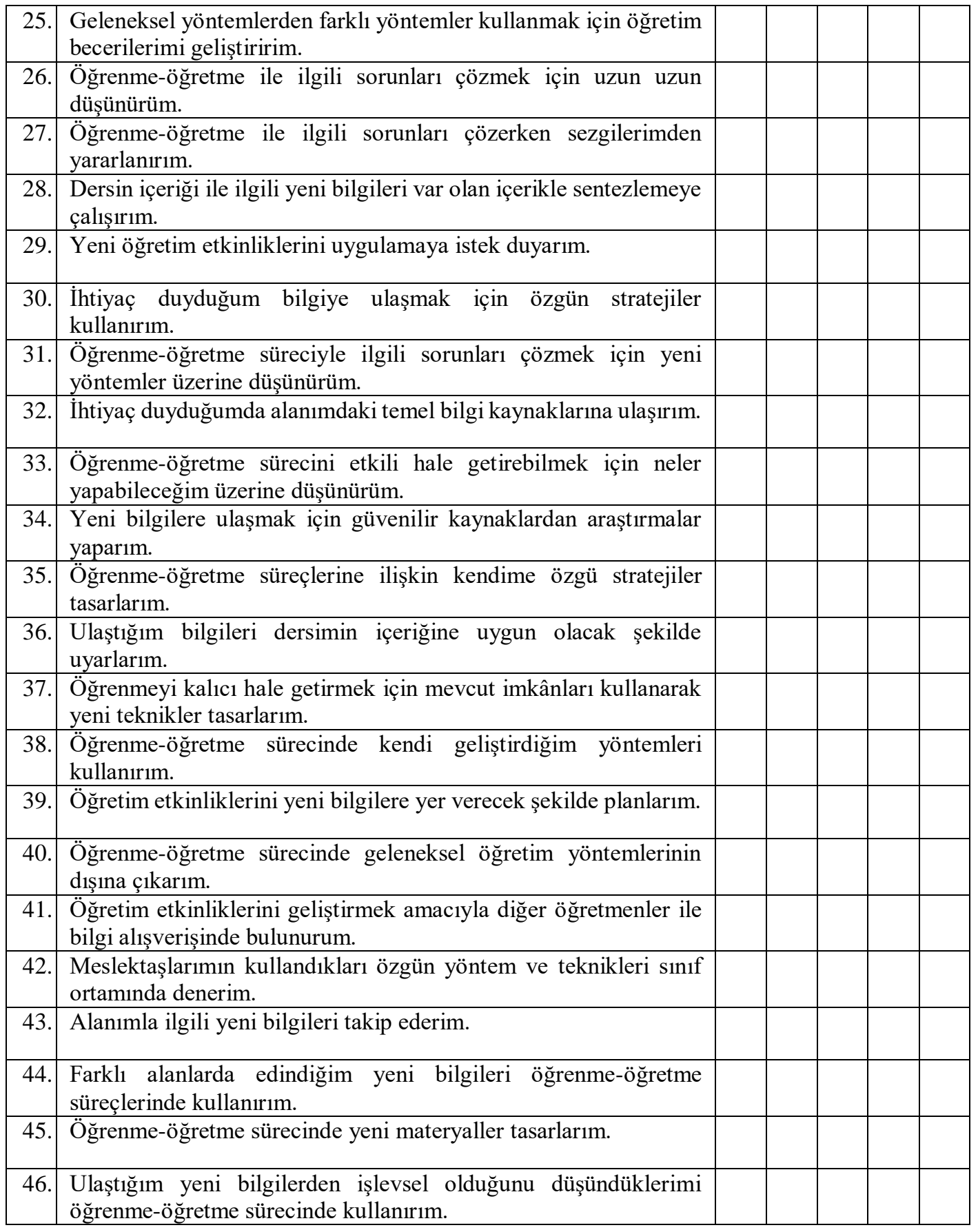

